\title{
QUALIDADE DA ÁGUA DE LAGOS E NASCENTES DO PARQUE DR. "FERNANDO COSTA" (ÁGUA BRANCA), SÃO PAULO, SP
}

\author{
M.S. Vieira' ${ }^{1}$, M.A.M. Moura' ${ }^{2}$, F.G. Gil ${ }^{3}$
}

${ }^{1}$ Instituto Biológico, Centro de Pesquisa e Desenvolvimento de Proteção Ambiental, Av. Cons. Rodrigues Alves, 1252, CEP 04014-002, São Paulo, SP, Brasil. E-mail: martiniana@biologico.sp.gov.br

\section{RESUMO}

Em maio de 1999, foram realizadas análises físicas e químicas da água em nascentes e lagos do Parque Dr. "Fernando Costa" (Parque Água Branca) São Paulo, SP, com o objetivo de determinar sua qualidade e propor medidas de preservação. Para tanto, foram escolhidos 6 pontos amostrais, na superfície e fundo do Lago Negro, nas nascentes da Horta e do Ranário e nos Tanques do Chafariz e das Carpas. Os maiores níveis de oxigênio dissolvido foram encontrados no Lago Negro (12 na superfície e $12,70 \mathrm{mg} / \mathrm{L}$ no fundo), sendo que apenas nas nascentes estes valores foram inferiores ao estipulado pela legislação CONAMA 357/2005, para Águas Doces Classe III (> 4 mg/L). Somente do Lago Negro, tanto na superfície quanto no fundo, foram encontrados valores de cor acima do limite estipulado pela legislação (até $75 \mathrm{mg} \mathrm{Pt} / \mathrm{L}$ ). Altos valores de $\mathrm{DBO}^{5}$ foram encontrados apenas nos Tanques das Carpas $(9,29 \mathrm{mg} / \mathrm{L})$ e do Chafariz $(11,22 \mathrm{mg} / \mathrm{L})$. Para todos os ambientes, os valores $\mathrm{N}-\mathrm{NO}_{2}$ estiveram acima do limite estabelecido $(1 \mathrm{mg} / \mathrm{L})$, sendo que, em relação ao $\mathrm{N}-\mathrm{NO}_{3}$, somente nas nascentes estes valores foram iguais ou superiores ao limite estabelecido $(10 \mathrm{mg} / \mathrm{L})$. Através da análise dos resultados, foi possível observar que as águas do Parque Água Branca apresentam boa qualidade para fins ecológicos e paisagísticos. Entretanto, o crescimento urbano desordenado, sem considerar a preservação de nascentes e áreas verdes, e o elevado aporte de matéria orgânica, principalmente no Lago Negro, são fatores relevantes na perda de qualidade da água. Somente um planejamento urbano aliado a um programa de educação ambiental, poderá auxiliar na melhoria das condições ecológicas e sanitárias desta importante área verde na região central de São Paulo.

PALAVRAS-CHAVE: Parques urbanos, qualidade da água, eutrofização.

\section{ABSTRACT}

THE QUALITY OF THE WATER OF SPRINGS AND PONDS AT DR. "FERNANDO COSTA" (ÁGUA BRANCA) PARK, SÃO PAULO, SP. In May 1999, physical and chemical analyses of water was carried out at springs and ponds in Dr. "Fernando Costa" Park, São Paulo, SP, Brazil, with the aim of determining its quality and propose preservation measures. Six sampling points were used, at the surface and bottom of Negro Lake, at Horta and Ranário springs and in the Chafariz and Carpas tanks. The largest levels of dissolved oxygen were found in Negro Lake (12.0 at the surface and $12.70 \mathrm{mg} / \mathrm{L}$ at the bottom), and only in the springs were these values below that stipulated by the CONAMA 357/2005 legislation, for Class III Fresh Water $(>4.0 \mathrm{mg} / \mathrm{L})$. Only in Negro Lake, at the surface and at the bottom, were there found color values above the limit stipulated by the legislation (up to $75.0 \mathrm{mg} \mathrm{Pt} / \mathrm{L}$ ). High values of $\mathrm{DBO}^{5}$ were only found in the Carpas $(9.29 \mathrm{mg} /$ L) and Chafariz tanks (11.22 mg/L). For all environments, $\mathrm{N}-\mathrm{NO}_{2}$ values were above the established limit $(1.0 \mathrm{mg} / \mathrm{L})$, and in relation to $\mathrm{N}-\mathrm{NO}_{3}$, only in the springs were these values equal to or higher than the established limit $(10.0 \mathrm{mg} / \mathrm{L})$. The results showed that the waters in Dr. Fernando Costa Park present good quality for ecological and landscape purposes. However, the disordered urban growth, without considering the preservation of springs and green areas, and the high contribution of organic matter, mainly in Negro Lake, are important factors in the loss of quality of the water. Only urban planning in conjunction with an environmental education program can aid in the improvement of ecological and sanitary conditions of this important green area in the central area of the city of São Paulo.

KEY WORDS: Urban parks, water quality, eutrophication.

2Pólo Regional de Desenvolvimento Tecnológico dos Agronegócios do Centro-Sul, Piracicaba, SP, Brasil. ${ }^{3}$ Universidade São Marcos, São Paulo, SP, Brasil. 


\section{INTRODUÇÃO}

Os sistemas urbanos industriais são classificados, tendo por base a energia, como ecossistemas movidos a combustíveis, geradores de riqueza e de poluição, que substituem o sol como a principal fonte de energia. Estes sistemas são totalmente dependentes de outros, naturais e agrícolas e requerem uma quantidade extremamente grande de energia. Nestes locais, da forma como é gerada, não só a energia solar não é aproveitada, como se torna um incômodo, devido ao aquecimento do concreto, contribuindo para a geração do " smoog" fotoquímico, tornando as condições de vida extremamente desconfortáveis para os habitantes das cidades (ODum, 1983). A formação de grandes aglomerados urbanos, com crescentes necessidades de água para abastecimento doméstico, industrial, irrigação e lazer, torna a água um dos recursos fundamentais para a manutenção de uma grande cidade, sendo fundamental na harmonia da paisagem urbana e na melhoria do clima local (MARGALEFF, 1983).

A distribuição da água no planeta é heterogênea e apenas 2,5 a $3 \%$ do total, é doce. Nos continentes europeu easiático, quecorrespondem cerca de $60 \%$ da população mundial, a disponibilidade de água é de apenas 30\% do total (EsTeves, 1998; TundisI, 2003). Assim, o crescimento populacional está limitado pela disponibilidade de água. Alguns teóricos chegam a afirmar queo problema do futuro da humanidadenão está na escassez de combustível fóssil, mas sim, no déficit de água doce (Esteves, 1998).

Pesquisas recentes apontam para a discussão dos problemas ambientais como um sinônimo de combate à superpopulação. Ainda que seja considerado um tabu, com um aumento anual da ordem de 76 milhões de pessoas no planeta, qualquer ação ambiental que não leve em consideração o controle de natalidade, terá um sucesso limitado e a qualidade de vida eo bem estar das futuras gerações estarão comprometidos (RAPLEY, 2006).

No Brasil, apesar dos múltiplos usos que caracterizam os ambientes aquáticos urbanos (irrigação, doméstico, navegação, recreação e turismo), o seu estudo é pouco freqüente, salvos exceções tais como o Lago Paranoá (DF) e o Lago da Pampulha, MG, que têm sido estudados sob vários aspectos. O primeiro, situado na região urbana de Brasília, foi formado artificialmente e recebe um aporte contínuo denutrientes decorrentes dos lançamentos de esgotos sanitários brutos e/ ou tratados (Alves et al., 1988). Estudos sobre diversos aspectos ecológicos deste lago foram realizados por Pinto-Coelho (1983; 1987), Freitas (1983), Gani (1984), Toledo et al. (1988), Branco (1991), Starling (1993) e Rocha; Fonseca (1997). O Lago da Pampulha, periurbano, embora seja considerada área de lazer e patrimônio cultural da Cidade de Belo Horizonte, apresenta-se com problemas quanto à qualidade da água, devido à contaminação por esgotos domésticos (GIANI et al., 1988; Pinto; Coelho, 1987).

Para as águas dos inúmeros parques localizados na região metropolitana de São Paulo, ainda são raros os estudos, podendo-se citar os trabalhos de SCHADEN (1970) na Raia Olímpica da Cidade Universitária; RoCHA; NARDUZzo (1975) nos lagos do Parque Zoológico; Eysink (1985), Beiruth, (1993) e Pinheiro (2001) no Parque Ecológico do Tietê eGIL-GIL (2004), no Parque Estadual das Fontes do Ipiranga. Mais raros que estudos voltados para a qualidade física e química da água são os trabalhos sobre microorganismos indicadores da qualidade da água em parques urbanos de São Paulo. No entanto, num contexto geral, MARTINS et al. (1989) demonstraram a importância de estudos microbiológicos para ecossistemas aquáticos e Amaralet al. (2006) eCunHA et al. (2004) quanto a qualidade sanitário desses ambientes.

Embora numerosos, os parques espalhados por São Paulo, devido às suas dimensões, são insuficientes quando comparados às questões da necessidade e densidade populacionais. Após períodos de grande adensamento, como feriados e finas de semana prolongados, é grande a degradação dos parques, com aumento do aporte de lixo nos corpos d'água. Infelizmente, um trabalho de conscientização da sociedade quanto à necessidade premente de conservar as águas dacidadeé mais raro que os estudos dequalidade. Em geral, nas grandes cidades, as campanhas veiculadas na mídia dizem respeito ao uso racional da água tratada, porém não fazem menção à conservação das águas naturais urbanas.

Os estudos sobre a qualidade da água de parques metropolitanos de São Paulo revelaram um estado adiantado de degradação ecológica e sanitária (PINHEIRO, 2001; GIL-GIL, 2004). Em relação ao Parque Dr. "Fernando Costa", o presente estudo é pioneiro no que se refere à determinação da qualidade de suas águas e planejamento de uso e manejo.

De acordo com o exposto, o objetivo deste estudo foi determinar a qualidade física, química e bacteriológica da água das nascentes, tanques e lagos do parque Dr. "Fernando Costa", também conhecido como Parque Água Branca, localizado na Zona Oeste da Cidade de São Paulo. Os resultados servem como base para o planejamento do uso destas águas, tais como recreação, pesca e repovoamento com peixes ornamentais, assim como de medidas mitigadoras de problemas de degradação, de modo a tornar sustentável todo o sistema hídrico desse patrimônio ecológico encerrado em área tipicamente urbana. 


\section{Área de estudo}

O Parque Água Branca $\left(23^{\circ} 25^{\prime} \mathrm{S}\right.$ e $\left.46^{\circ} 28^{\prime} \mathrm{W}\right)$ foi criado em 1905, na Freguesia da Água Branca, pela prefeitura da Cidade de São Paulo, tendo sua administração transferida para o governo do Estado (Secretaria da Agricultura e Abastecimento) em 1929, quando passou a chamar-se Dr. "Fernando Costa". A finalidade era abrigar órgãos de pesquisa agropecuária, associações de criadores, promover leilões e exposições de animais e provas zootécnicas. O Parque é a única área verde relevante da região Oeste da capital, possuindo uma área total de $136.765 .41 \mathrm{~m}^{2}$, sendo $79.309,66 \mathrm{~m}^{2}$ não pavimentados e não edificados; $27.110 \mathrm{~m}^{2}$ de área edificada e $30.345,7 \mathrm{~m}^{2}$ de área pavimentada (ruas, alamedas e pátios) e uma grande diversidade faunística e florística. Foi revitalizado e tombado em 1996 como bem cultural, histórico, arquitetônico, turístico, tecnológico e paisagístico, pelo CONDEPHAAT (Conselho de Defesa do Patrimônio Histórico, Arqueológico, Artístico e Turístico do Estado), com o objetivo de garantir a preservação de uma importante área verde para a população paulistana (MARTINS, 1991).

OBairro da Água Branca foi formado em uma área próxima à várzea dos Vales do ribeirão Água Branca, hoje Av. Sumaré, e ribeirão Pacaembu, ambos afluentes do rio Tietê. No passado, afloravam inúmeras nascentes de rios e córregos de águas límpidas, pertencentes a estas microbacias. Atualmente, a maior parte destas nascentes foi extinta ou canalizada, restandoapenas 6, localizadas no Parque Dr. "Fernando Costa". Destas nascentes, 3 foram canalizadas para abastecer os tanques de Carpas e do Chafariz, que adornam a entrada principal do parque. As outras três nascentes, da Horta, do Ranário e da Bananeira, encontram-se ainda em condições naturais e, juntas formam o Lago Negro.

\section{MATERIAL E MÉTODOS}

\section{Parâmetros físicos e químicos}

Foram realizadas coletas de água no Lago Negro, nascentes da Horta e do Ranário e nos tanques das carpas e do chafariz do parque Parque Dr. "Fernando Costa", com amostragens em maio de 1999, sendo eleito um ponto por ambiente. Os parâmetros analisados podem ser observados na Tabela 1. No Lago Negro (Fig. 1) e (Tabela 2), o ponto de amostragem localizou-se no centro do corpo aquático e as coletas foram realizadas na superfície e no fundo da coluna d'água. Nas nascentes da Horta (Fig. 3) e do Ranário, a amostragem foi efetuada junto ao olho d'água. Nos tanques de Carpase doChafariz, apenas na superfície, pois o fundo dos referidos tanques é de alvenaria e a profundidade do espelho d'água é de apenas $1 \mathrm{~m}$. Para o Lago Negro, as coletas foram realizadas na superfície e no fundo da coluna d'água.

Tabela 1 - Parâmetros físicos e químicos e metodologia empregada para a determinação da qualidade da água.

\begin{tabular}{lll}
\hline Parâmetros & Unidades & Métodos \\
\hline $\begin{array}{l}\text { Profundidade } \\
\mathrm{pH}\end{array}$ & $\mathrm{m}$ & Profundidímetro \\
Condutividade elétrica & $\mu \mathrm{S} / \mathrm{cm}$ & Water Analyser \\
Temperatura & ${ }^{\circ} \mathrm{C}$ & Water Analyser \\
Oxigênio dissolvido & $\mathrm{ppm}$ & Water Analyser \\
$\mathrm{Cor}$ & $\mathrm{mg} / \mathrm{LPT}$ & Water Analyser \\
Turbidez & $\mathrm{NTU}$ & Colorímetro Rach \\
$\mathrm{DBO}$ & $\mathrm{ppm}$ & Turbidímetro \\
$\mathrm{Fe}$ & $\mathrm{ppm}$ & Titulométrico (APHA, 1992) \\
$\mathrm{PO}_{4}$ & $\mathrm{ppb}$ & Espectrofotométrico (APHA, 1992) \\
$\mathrm{NH}_{3}$ & $\mathrm{ppb}$ & Espectrofotométrico (APHA, 1992) \\
$\mathrm{NO}_{2}$ & $\mathrm{ppm}$ & Espectrofotométrico (APHA, 1992) \\
$\mathrm{NO}_{3}$ & $\mathrm{ppm}$ & Espectrofotométrico (APHA, 1992) \\
Dureza total & $\mathrm{ppm}$ & Espectrofotométrico (APHA, 1992) \\
$\mathrm{Ca}^{++}$ & $\mathrm{ppm}$ & Titulométrico (APHA, 1992) \\
$\mathrm{Alcalinidade}_{\mathrm{Cl}^{-}}$ & $\mathrm{ppm}$ & Titulométrico (APHA, 1992) \\
$\mathrm{Oxigên}^{+}$ & $\mathrm{ppm}$ & Titulométrico (APHA, 1992) \\
\hline & $\mathrm{ppm}$ & Titulométrico (APHA, 1992) \\
\hline
\end{tabular}




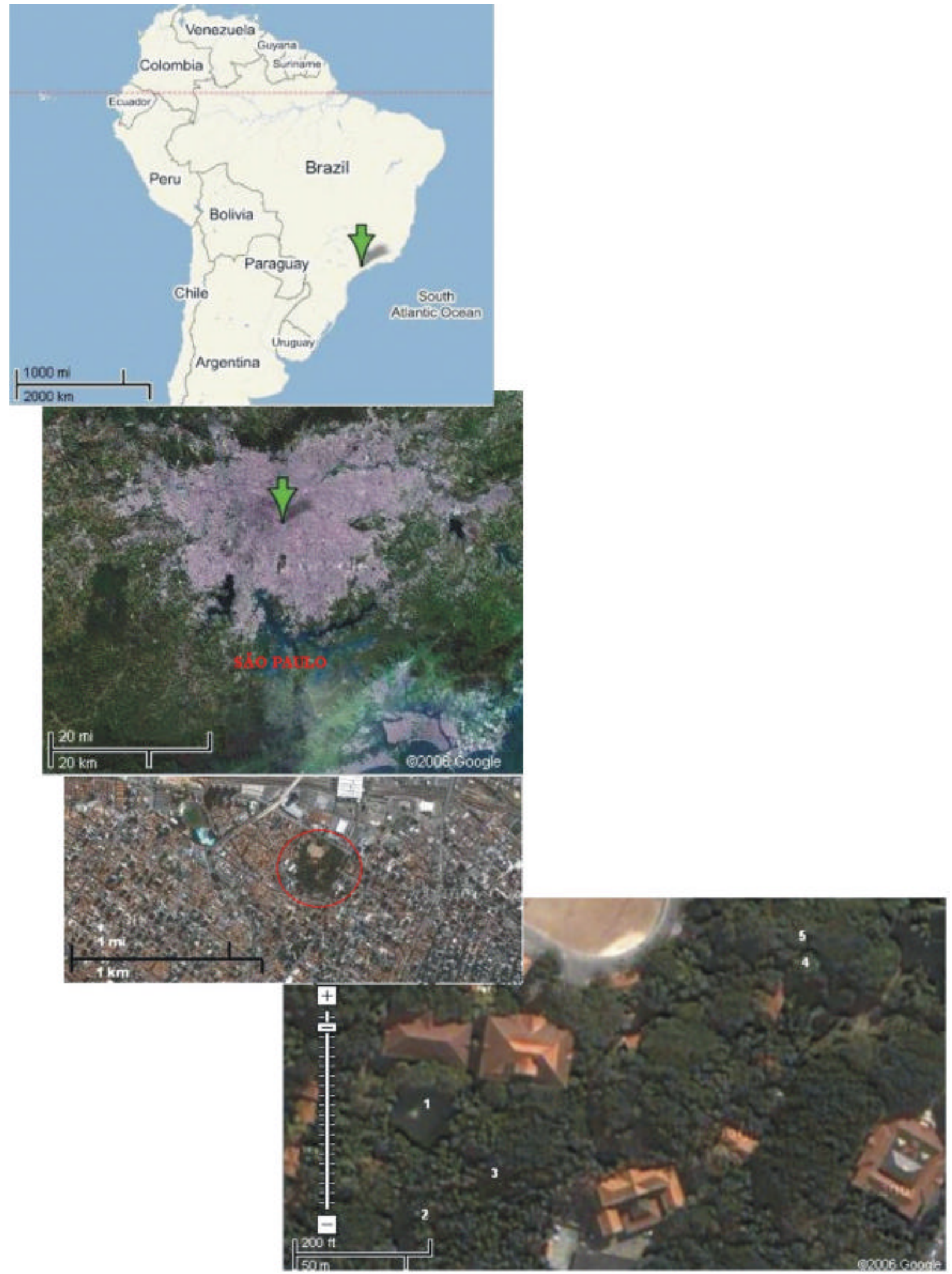

Fig. 1 - Localização dos pontos de coleta (Fonte: Google Maps) (1 - Lago Negro; 2 - Nascente do Ranário; 3 - Nascente da Horta; 4- Tanque do Chafariz e 5 - Tanque das Carpas). 
Tabela 2 - Pontos de coleta georeferenciados.

\begin{tabular}{lll}
\hline Ponto de Coleta & Latitude & Longitude \\
\hline Tanque do Chafariz & $23^{\circ} 31^{\prime} 47,9^{\prime \prime} \mathrm{S}$ & $046^{\circ} 40^{\prime} 06,4^{\prime \prime} \mathrm{W}$ \\
Tanque das Carpas & $23^{\circ} 31^{\prime} 47,1^{\prime \prime} \mathrm{S}$ & $046^{\circ} 40^{\prime} 04,7^{\prime \prime} \mathrm{W}$ \\
Lago Negro & $23^{\circ} 32^{\prime} 49,7^{\prime \prime} \mathrm{S}$ & $046^{\circ} 40^{\prime} 11,9^{\prime \prime} \mathrm{W}$ \\
Nascente da Horta & $23^{\circ} 32^{\prime} 51,2^{\prime \prime} \mathrm{S}$ & $046^{\circ} 40^{\prime} 11,8^{\prime \prime} \mathrm{W}$ \\
Nascente do Ranário & $23^{\circ} 32^{\prime} 52,6^{\prime \prime} \mathrm{S}$ & $046^{\circ} 40^{\prime} 12,8^{\prime \prime} \mathrm{W}$ \\
\hline
\end{tabular}

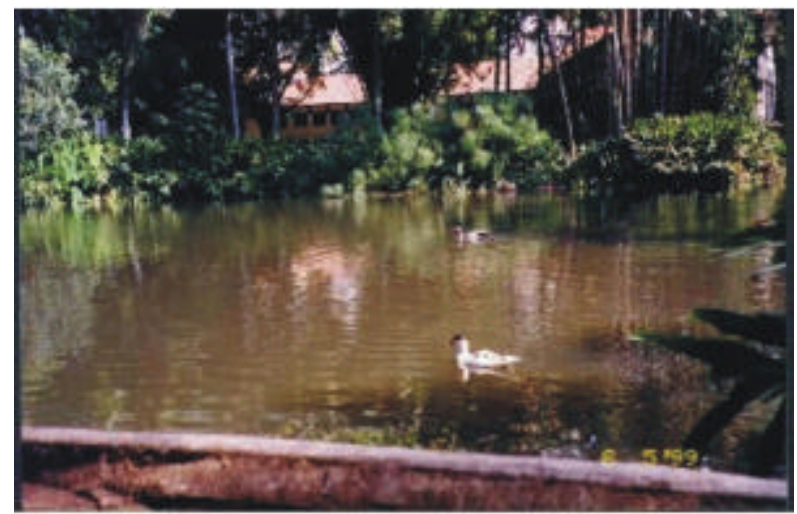

Fig. 2 - Lago Negro, Parque Dr. "Fernando Costa" (Água Branca), São Paulo, SP.

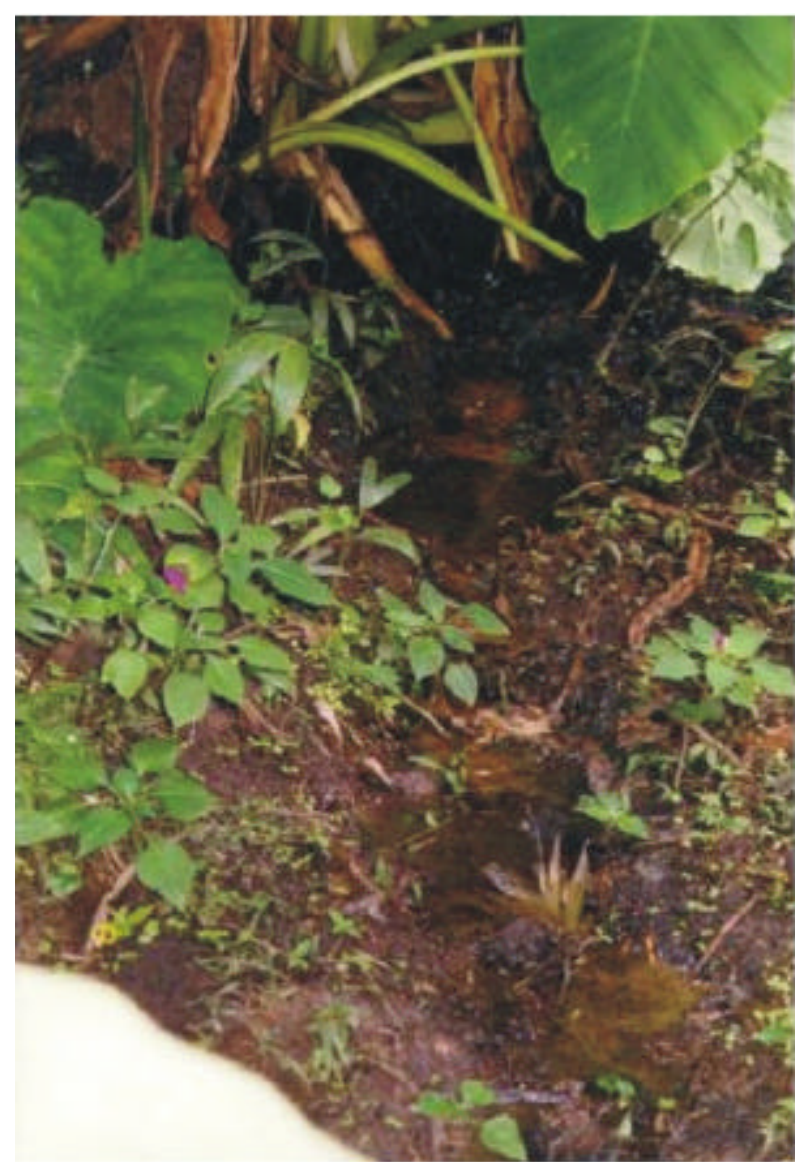

Fig. 3 - Nascente da Horta, Parque Dr. "Fernando Costa" (Água Branca), São Paulo, SP.

\section{Parâmetros microbiológicos}

As análises microbiológicas foram realizadas no Departamento de Saúde Ambiental da Faculdade de Saúde Pública da USP. Para tanto, foram utilizados para coleta recipientes assépticos de $100 \mathrm{~mL}$, em 6 pontos distintos do Lago Negro. As amostras foram analisadas quanto à presença de bactérias dos grupos coliformes totais e fecais, utilizando-se o reagente Colilert (APHA 1992). As amostras de água foram abertas segundo a metodologia padrão, para se manter a devida assepsia de contato com o material a ser examinado. Uma alíquota de $100 \mathrm{~mL}$ foi retirada da embalagem por meio de pipeta estéril e colocada em um frasco, que foi agitado até a completa diluição dos grânulos. A solução foi colocada em uma cartela composta de 51 cúpulas, que foi colocada em uma seladora e a solução distribuída igualmente. Em seguida, a solução foi incubada a $35^{\circ} \mathrm{C}$ em estufa por 24hs. A leitura foi feita com auxílio de uma lâmpada ultravioleta (115 volts, 6hz, 20 AMPS), quando da presença de coloração amarela na solução da cartela. O teste era positivo para coliforme total se a cúpula mantivesse a coloração amarela e, para coliforme fecal se apresentasse coloração azul. O teste era negativo com ausência de coloração. Os resultados foram expressos de acordo com a tabela NMP (número mais provável em $100 \mathrm{~mL}$ de água), onde uma cúpula positiva equivale a uma bactéria em $100 \mathrm{~mL}$ de água.

\section{RESULTADOS E DISCUSSÃO}

Através dos resultados obtidos neste estudo foi possível demonstrar que a qualidade das águas do Parque Dr. "Fernando Costa" ainda pode ser considerada boa para fins ecológicos. Para os Tanques das Carpas e do Chafariz, os baixos valores de Demanda Bioquímica de Oxigênio (DBO), altas concentrações de oxigênio dissolvido e as baixas de nutrientes (Tabela 3), indicaram que estes tanques apresentam boa qualidade de água, apesar do Tanque das Carpas apresentar $\mathrm{pH}$ com tendência ácida. Já os valores encontrados, para os mesmos parâmetros, na superfície e fundo do Lago Negro e para as Nascentes da Horta e do Ranário, indicaram níveis preocupantes de contaminação (Tabelas 3 e 4).

Os altos valores de $\mathrm{pH}$, oxigênio dissolvido e $\mathrm{DBO}$, aliados aos elevados valores de condutividade elétrica, nitrato $\left(\mathrm{N}_{-} \mathrm{NO}_{3}^{-}\right)$, nitrito $\left(\mathrm{N}-\mathrm{NO}_{2}^{-}\right)$, amônia $\left(\mathrm{N}-\mathrm{NH}_{4}^{+}\right)$ e fosfato $\left(\mathrm{P}_{-} \mathrm{PO}_{4}{ }^{2-}\right)$, permite supor um franco processo de eutrofização no Lago Negro. Este último recebe uma considerável contribuição de matéria orgânica vinda da adubação de uma horta e da fauna ali estabelecida, constantemente alimentada pelos visitantes, ainda que haja sinalização proibindo esta 
prática. Esforços no sentido de aerar a água do lago já foram providenciados. No entanto, com a construção de um edifício na rua Ministro deGodoy, as nascentes que abastecem o lago diminuíram consideravelmente o volume de água, sendo este um fator negativo, quanto à melhoria da qualidade da água. Outra providência importante a ser tomada seria implantar um programa de educação e conscientização da população freqüentadora do Parque, minimizando, assim, os problemas de eutrofização deste ambiente.

No presente estudo, não foi observado um decréscimo acentuado de oxigênio dissolvido nas regiões mais profundas da coluna d'água (Tabelas 3). Em relação às Nascentes, os baixos valores de oxigênio dissolvido justificam-se pelo fato de se tratar de um afloramento de águas subterrâneas, com baixas concentrações deste gás; e pela ausência da comunidade fitoplanctônica, que ainda não se estabeleceu neste ambiente, notadamente lótico e de águas transparentes (KLeEReKoper, 1990). As mesmas condições de supersaturação de oxigênio dissolvido (> $9 \mathrm{mg} / \mathrm{L}$ ) foram encontradas para dois lagos rasos (profundidade média de 1,5 m) de parques urbanos de Londres, Inglaterra (STOIANOV et al., 2000), sendo estes valores atribuídos à fotossíntese realizada pela grande massa de fitoplâncton presente naqueles ambientes.

Tabela 3 - Parâmetros físicos e químicos de qualidade da água do Parque da Água Branca e valores de referência da Resolução CONAMA ${ }^{1}$.

\begin{tabular}{|c|c|c|c|c|c|c|c|}
\hline \multirow[t]{2}{*}{ Parâmetros } & \multirow[t]{2}{*}{$\begin{array}{l}\text { Limites } \\
\text { CONAMA }\end{array}$} & \multicolumn{6}{|c|}{$\begin{array}{c}\text { Parque da } \\
\text { Água Branca }\end{array}$} \\
\hline & & $\begin{array}{l}\text { Lago } \\
\text { Negro } \\
\text { superfície }\end{array}$ & $\begin{array}{l}\text { Lago } \\
\text { Negro } \\
\text { fundo }\end{array}$ & $\begin{array}{c}\text { Nascente } \\
\text { Horta }\end{array}$ & $\begin{array}{l}\text { Nascente } \\
\text { Ranário }\end{array}$ & $\begin{array}{c}\text { Tanque das } \\
\text { Carpas }\end{array}$ & $\begin{array}{r}\text { Tanque do } \\
\text { Chafariz }\end{array}$ \\
\hline Cor $(\mathrm{mg}$ Pt.L-1 $)$ & Até 75,00 & 87,00 & 120,0 & 12,0 & 2,00 & 13,00 & 36,00 \\
\hline $\mathrm{pH}$ & 6,00 a 9,00 & 9,19 & - & 5,37 & 5,19 & 5,92 & - \\
\hline Tubidez (NTU) & Até $1.000,00$ & 7,50 & 11,00 & 2,50 & 2,00 & 2,50 & 4,80 \\
\hline \multicolumn{8}{|l|}{$\mathrm{PO}_{4}\left(\mathrm{mg} \cdot \mathrm{L}^{-1}\right)$} \\
\hline ambiente lêntico & 150,00 & 50,00 & 80,90 & - & - & 16,20 & 20,50 \\
\hline ambiente lótico & 450,00 & - & - & 27,00 & 5,90 & - & - \\
\hline \multicolumn{8}{|l|}{$\mathrm{N}-\mathrm{NH}_{3}\left(\mathrm{mg} \cdot \mathrm{L}^{-1}\right)$} \\
\hline em $\mathrm{pH} \mathrm{d}^{\prime \prime} 7,5$ & $13.300,00$ & - & - & 0,15 & 2,79 & 0,15 & 0,15 \\
\hline em $\mathrm{pH}>8,5$ & $1.000,00$ & 0,31 & 0,54 & - & - & - & - \\
\hline DBO 5 dias a $20^{\circ} \mathrm{C}\left(\mathrm{mg} . \mathrm{L}^{-1}\right)$ & 10,00 & 1,36 & 0,97 & - & - & 9,29 & 11,22 \\
\hline $\mathrm{Fe}\left(\mathrm{mg} \cdot \mathrm{L}^{-1}\right)$ & 5,00 & 0,10 & 0,33 & 0,08 & 0,02 & 0,02 & 0,07 \\
\hline $\mathrm{N}-\mathrm{NO}_{2}\left(\mathrm{mg} \cdot \mathrm{L}^{-1}\right)$ & $1,00 \mathrm{mg} / \mathrm{L}$ & 34,60 & 34,20 & 8,52 & 12,90 & 6,25 & - \\
\hline $\mathrm{N}-\mathrm{NO}_{3}\left(\mathrm{mg} \cdot \mathrm{L}^{-1}\right)$ & $10,00 \mathrm{mg} / \mathrm{L}$ & 3,86 & 4,72 & 10,91 & 9,99 & 7,67 & 1,61 \\
\hline Cloreto (mg. $\mathrm{L}^{-1}$ ) & $250,00 \mathrm{mg} / \mathrm{L}$ & 18,27 & 17,69 & 19,43 & 18,56 & 17,98 & 11,60 \\
\hline Oxigênio dissolvido (mg. $\left.\mathrm{L}^{-1}\right)$ & $>4,00 \mathrm{mg} / \mathrm{L}$ & 12,00 & 12,35 & 3,50 & 3,20 & 9,40 & - \\
\hline Oxigênio consumido (mg. $\mathrm{L}^{-1}$ ) & - & 4,56 & 6,32 & 1,63 & 1,22 & 2,55 & 5,92 \\
\hline $\mathrm{Ca}^{2+}\left(\mathrm{mg} \cdot \mathrm{L}^{-1}\right)$ & - & 10,27 & 8,69 & 5,53 & 3,95 & 10,27 & 9,48 \\
\hline Alcalinidade $\left(\mathrm{mg} \cdot \mathrm{L}^{-1}\right)$ & - & 36,20 & 36,20 & 8,50 & 10,70 & 21,30 & 29,80 \\
\hline Dureza $\left(\mathrm{mg} . \mathrm{L}^{-1}\right)$ & - & 41,58 & 31,68 & 21,78 & 23,76 & 33,66 & 35,64 \\
\hline Condutividade elétrica $(\mu \mathrm{S} / \mathrm{cm})$ & m) - & 114,0 & - & 165,0 & 177,0 & 228,5 & - \\
\hline Temperatura $\left({ }^{\circ} \mathrm{C}\right)$ & - & 24,2 & - & 23,8 & 25,3 & 23,2 & - \\
\hline
\end{tabular}

${ }^{1}$ Modificado da Resolução CONAMA, No 357 de 2005, para Águas Doces, Classe III.

Tabela 4 - Parâmetros bacteriológicos determinados para os diferentes ambientes aquáticos estudados no Parque da Água Branca e valores de referência da Resolução CONAMA ${ }^{1}$.

\begin{tabular}{|c|c|c|c|c|c|c|}
\hline Coliformes termotolerantes ( $\mathrm{n}^{\circ}$ indivíduos $/ 100 \mathrm{~mL}$ ) & & & & & & \\
\hline recreação de contato $2^{\text {ario }}$ & 14 & - & 4 & 2 & 2 & $<2$ \\
\hline Coliformes totais $\left(\mathrm{n}^{\circ}\right.$ indivíduos/100 mL) & 50 & - & 9 & 5 & 4 & 6 \\
\hline
\end{tabular}

${ }^{1}$ Modificado da Resolução CONAMA, No 357 de 2005, para Águas Doces, Classe III. 
Em relação à cor e a turbidez, observou-se os maiores valores para o Lago Negro (fundo > superfície), seguido dos Tanques de Carpa e do Chafariz e, por último das Nascentes. SegundoBARreto(1999), os sólidos em suspensão podem interferir na concentração de oxigênio e na condutividade elétrica, contribuindo, também, para a coloração da água e a DBO.Suas principais fontes são o silte, o sedimento drenado, as fezes das aves aquáticas e a resuspensão do sedimento (StOIANov et al., 2000). Estes dois últimos, sendo encontrados no Lago Negro, que apresenta abundante cardume de carpas comum (Cyprinus carpio), uma espécie bentônica, revolvedora de sedimento de fundo (Scott \& Crossman, 1973). Os tanques de Carpas e do Chafariz são artificiais, apresentado o fundo e as laterais cimentadas.

O nitrogênio está presente nos ambientes aquáticos sob várias formas, por exemplo, nitrato $\left(\mathrm{N}-\mathrm{NO}_{3}^{-}\right)$, nitrito $\left(\mathrm{N}_{-} \mathrm{NO}_{2}^{-}\right)$, amônia $\left(\mathrm{N}-\mathrm{NH}_{3}\right)$, íon amônio $(\mathrm{N}$ $\left.\mathrm{NH}_{4}^{+}\right)$, óxido nitroso $\left(\mathrm{N}-\mathrm{N}_{2} \mathrm{O}\right)$, nitrogênio molecular $\left(\mathrm{N}_{2}\right)$, nitrogênio orgânico dissolvido (peptídeos, purinas, aminas, aminoácidos etc) e nitrogênio orgânico particulado (bactérias, fitoplâncton, zooplâncton e detritos) (Esteves, 1998). No Lago Negro os altos valores de amônia e elevado $\mathrm{pH}$, demonstram que pode estar ocorrendo um processo de amonificação no ciclo do nitrogênio, pois a mesma pode estar sendo hidrolizada para formar o íon $\mathrm{N}-\mathrm{NH}_{4}{ }^{+}$, tendo como produto da reação o íon hidroxila $\left(\mathrm{OH}^{-}\right)$, que acaba por elevar os valores de $\mathrm{pH}$. Outro processo que pode estar ocorrendo é o de nitrificação, aliado à ciclagem de compostos do nitrogênio alóctone. Este processo depende de alguns fatores ambientais tais como: temperatura da água entre 20 e $25^{\circ} \mathrm{C}$, pH entre 7,5 e 8,5 e teores de oxigênio acima de 1 ppm.

Os teores de $\mathrm{Mg}, \mathrm{Fe}, \mathrm{CO}_{2}$ e $\mathrm{PO}_{4}$ são indispensáveis à síntese microbiológica e o $\mathrm{Na}$ e o $\mathrm{Ca}$, ainda, são reguladores do $\mathrm{pH}$, neutralizando os ácidos nitroso e nítrico, produzidos durante este processo (Branco, 1986 apud MaIER et al., 1992). Concentrações superiores a $0,25 \mathrm{mg} \mathrm{N}-\mathrm{NH}_{3} / \mathrm{L}$ podem afetar o crescimento dos peixes, sendo que a $\mathrm{LC}_{50}$ para a $\mathrm{N}$ $\mathrm{NH}_{3}$ é bastante superior (=0,5mg/L) (TRUSSEL, 1972). Pela observação dos dados, nota-se que o Lago Negro não se apresenta acima destes limites ou dos estabelecidos pela resolução CONAMA $(0,13 \mathrm{mg} /$ L em pH dŠ 7,5; 0,1 mg/L em pH > 8,5, para águas Classe III) (ConAma, 2005).

A Nascente do Ranário foi a que apresentou os maiores valores de composto de nitrogênio, principalmente $\mathrm{N}-\mathrm{NO}_{2}$ e N-NO . Provavelmente estes altos valores se devam ao fato desta nascente localizar-se em um reservatório escavado logo abaixo do escritório do Ranário, onde há acúmulo consideravelmente alto de detritos. Já a Nascente da Horta está localizada em uma área adubada. Ambas abastecem o Lago Negro.

Para todos os ambientes, os valores de $\mathrm{Ca}$ e $\mathrm{Cl}$ estiveram dentro de limites aceitáveis. Os valores de alcalinidade e dureza totais da água podem, também, juntamente com outros fatores já mencionados, podem contribuir para uma elevação do $\mathrm{pH}$.

A presença de bactérias termotolerantes (coliformes fecais e totais), usadas como indicadores da qualidade sanitária da água, é um indicativo da existência de outros organismos patogênicos (MeHnert;Stewein, 1993). Os coliformes fecais são os organismos mais utilizados na avaliação da qualidade da água, quanto ao aspecto sanitário (MARTINS et al., 1989).

No Lago Negro foram encontrados os maiores valores por $\mathrm{mL}$ (Tabela 3). As águas do parque destinam-se a fins paisagístico e ecológico, sendo classificadas como Classes III (contato secundário) e IV (harmonia paisagística), com um limite de concentração de até $2,5 \times 10^{3}$ bactérias termotolerantes /100 mL, bem superiores ao limite das águas Classe II (até $10^{3}$ bactérias termotolerantes /100 mL), destinada à aqüicultura (CONAMA, 2005). Observa-se, então, queas águas do Parque estão dentro do limite estabelecido pela legislação.

\section{CONCLUSÃO}

As águas do Parque Água Branca podem ser consideradas como de boa qualidade para fins ecológico e paisagístico. Entretanto, é preciso ressaltar o franco processo de eutrofização do Lago Negro, que recebe elevado aporte de matéria orgânica. A presença de espécies de peixe revolvedoras de fundo contribui para a elevada concentração de material mineral em suspensão, o que também pode comprometer não somente o aspecto visual, mas também a qualidade deste corpo d'água em algumas épocas do ano. O crescimento urbano no entorno do Parque também é um fator relevante na perda de qualidade de suas águas, uma vez que o fluxo de água das nascentes foi reduzido, agravando os problemas de eutrofização. Somente um planejamento urbano que considere a preservação de nascentes e áreas verdes, aliado a um programa de educação ambiental, poderá auxiliar na melhoria das condições ecológicas e sanitárias desta importanteárea verde do Município de São Paulo.

Embora seja reconhecida pela comunidade locale a direção do parque Fernando Costa a necessidade de preservar as nascentes, até o presente momento este patrimônio ecológico não conta com um programa de monitoramento contínuo, sendo este oúnico trabalho realizado na área. 


\section{AGRADECIMENTOS}

Ao Instituto de Pesca/ APTA/SAA, pelo fornecimento da estrutura de laboratório para as análises. À Faculdade de Saúde Pública/USP, Departamento de Saúde Ambiental, pelas análises microbiológicas.

\section{REFERÊNCIAS}

Alves, V.R.E., Cavalcanti, C.G.B.; Mattos, S.P. Análise comparativa de parâmetros físicos, químicos e biológicos, em um período de 24 horas, no Lago Paranoá, Brasília, DF, Brasil. Acta Limnologica Brasilensia, v.2, p.119-121, 1988.

Amaral, A. L.; Nunes, A.P.; Castania, J.; Lorenzon, C.S.; BARROS, R.S.S.; N ADER FiLHO, A. Uso da radiação solar na desinfecção da água de poços rasos.Arquivos do Instituto Biológico,São Paulo, v.73, n.1, p.45-50, 2006. Disponível em <http://www.biologico.sp.gov.br/ ARQUIVOS/V73_1/index.htm>. Acesso em: 5 out. 2006.

American Public Health Association. Standard Methods for the examination of water and wastewater. 18.ed. Washington, DC: APHA, 1992.

BEIRUTH, Z. Fitoplâncton em lagos do Parque Ecológico do Tietê, São Paulo, 1986-1987. Estudo para reabilitação. Revista Departamento de Águas e Energia Elétrica, v.170, p.5-10, 1993.

Branco, C.W.C. A comunidade fitoplanctônica e a qualidade da água do Lago Paranoá, Brasília, DF, Brasil. 1991, 341p. Dissertação (Mestrado) - Departamento de Ecologia - Universidade Federal de Brasília, Brasília, 1991.

Branco, S.M. A água como meio ecológico. In: Branco, S.M. (Ed.). Hidrologia aplicada à engenharia sanitária, 3.ed. São Paulo: CETESB/ASCETESB, 1986. Apud MaIER, M.H.; TAKINO, M.; MANOEL, A.M.S. 1992 Amônia, nitrito, nitrato e ortofosfato na microbacia do Córrego Salto Grande: $22^{\circ} 09^{\prime} \mathrm{S}$ e $48^{\circ} 19^{\prime} \mathrm{W}$, Dourado, Brasil. Boletim do Instituto de Pesca, v.19 n.único, p.2328, 1992.

Conselho Nacional doMeio Ambiente - CONAMA,(Brasil). Dispõe sobre a classificação dos corpos de água e diretrizes ambientais para o seu enquadramento, bem como estabelece as condições e padrões de lançamento de efluentes, e dá outras providências. Resolução n.357, de 17 de março de 2005. Disponível em: < http://www.mma.gov.br/port/conama/res/ res05/res35705.pdf>. Acesso em: 13 jan. 2006.

CunHa, A.C.; AlbuQuerque, H.F.; Brasil, A.C.P. Daniel, L.A. Schulz, H.E. Qualidade microbiológica da água em rios deáreas urbanas e periurbanas no baixo Amazonas: o caso do Amapá. Revista de Engenharia Sanitária e Ambiental.v.9, n.4, p.104-107, 2004

Exsink, G.G.J. Caracterização ambiental dos lagos do PET. São Paulo: CETESB, 1985, 150p. [Relatório].

Esteves, F.A. Fundamentos delimnologia. 2.ed. Rio de Janeiro: Interciência, 1998. 602 p.
Freitas, J.S. Variação sazonal e distribuição vertical de microcrustáceos planctônicos no Lago Paranoá, DF, Brasília. 1983, 110p. Dissertação (Mestrado) - Universidade Federal de Brasília, Brasília, 1983.

GIL-GIL, F. Fracionamento da produção primária em dois sistemas com diferentes níveis tróficos no Parque Estadual das Fontes do Ipiranga, São Paulo. 2004, 145p. Tese (Doutorado) - Instituto de Biociências, Universidade de São Paulo, São Paulo, 2004.

Giani, A. Distribuição horizontal do fitoplâncton e zooplâncton no Lago Paranoá, DF, Brasília. 1984, 147p. Dissertação (Mestrado), Universidade Federal de Brasília, Brasília, 1984.

Giani, A.; Pinto-Coelho, R.M.; Olveira, S.J.M.; Pelli, A. Ciclo sazonal de parâmetros físicos e químicos da água e distribuição de nitrogênio e fósforo no reservatório da Pampulha (Belo Horizonte, MG, Brasil). Ciência e Cultura, v.40, n.1, p.69-77, 1988.

KLEEREKOPER, H. Introdução ao estudo da limnologia. 2.ed. Porto Alegre: Editora da Universidade/UFRGS,1990.329p.

Martins, Z. Agricultura Paulista: uma história maior que cem anos - São Paulo: Secretaria de Agricultura e Abastecimento do Estado deSão Paulo, 1991. Disponível em: <http://www.parqueaguabranca.sp.gov.br/>. Acesso em: 13 jan. 2006.

Martins, M.T., Gambale, W., Paula, C.R., Pellizari, V.H., Matsumoto, E.F., R ibeiro, G., Malateaux, S.; Maier,M.H. Utilização de bactérias e fungos como indicadores na avaliação de fatores fisiográficos que interferem nos processos de auto-depuração de um córrego subtropical. Revista de Microbiologia, v.20, n.3, p.278-291, 1989.

Mehnert, D.U.; Stewein, K.E. Detection and distribution of rotavirus in raw sewage and creeks in São Paulo, Brazil. Applied Environmental Microbiology, v.59, p.140143, 1993.

Pinheiro, C.H.R. Análise de diferentes fatores na disposição de metais pesados em sedimentos lacustres no Parque Ecológico do Tietê. 2001, 134p. Dissertação (Mestrado) Instituto de Geociências, Universidade de São Paulo, São Paulo, 2001.

Pinto-Coelho, R.M. Efeitos do zooplâncton na composição qualitativa e quantitativa no Lago Paranoá, DF, Brasília. 1983, 147p. Dissertação (Mestrado) - Universidade Federal de Brasília, Brasília, 1983.

Pinto-Coelho, R.M. Flutuações sazonais e de curta duração na comunidade zooplanctônica do Lago Paranoá, DF. Revista Brasileira de Biologia, v.47, n.1/2, p.17-29, 1987.

RAPLEY, C. Earth is too crowded for Utopia. VIEWPOINT. BBCNews, 2006. Disponívelem: $<$ http://news.bbc.co. $\mathrm{uk} / 2 / \mathrm{hi} /$ science/nature/4584572.stm $>$. Acesso em: 12 jan. 2006.

Rocha, D.L.P.; FonseCA, C.P. Estudo da dinâmica de populações de microcrustáceos no Braço do Riacho Fundo, Lago Paranoá, Brasília, DF. In: CONGRESSO BRASILEIRO DE LIMNOLOGIA, 6., 1997, SãoCarlos. Resumos. São Carlos, 1997, p.405.

RochA, A.A.; NARDUZZO, M. Aspectos ecológicos dos lagos do Parque Zoológico de São Paulo. Revista do Departamentode Águas e Energia Elétrica, v.35, n.103, p. 45-51, 1975 
SCHADEN, R. Sobre rotíferos planctônicos da Raia Olímpica da Cidade Universitária em São Paulo. 1970, 36p. Dissertação (Mestrado) - Instituto de Biociências, Universidade de São Paulo, São Paulo, 1970.

Scott, W.B.; C Rossman,E.J. Freshwater fishes of Canada. Bulletin Fisheries Research Board Canada, v.184, p.407-411, 1973.

StarLing, F.L.R.M. Análise experimental dos efeitos da tilápia do Congo (Tilapia rendalli) e carpa prateada (Hypophthalmichthys molitrix) sobre a estrutura da comunidade planctônica do Lago Paranoá, Brasília(DF). Acta Limnologica Brasiliensia, v.6, p.144-156, 1993.

Stolanov,I., C HAPRA,S.; MaKsimovic, C. A framework linking urban park land use with pond water quality. Urban Water, v.2, p.47-62, 2000.
Toledo, L.G.;Freitas, J.S; Ferreira, C.J.A. Variação diurna de parâmetros limnológicos do Lago Paranoá, Brasília, DF, Brasil. Acta Limnologica Brasiliensia, v.2, p.219-237, 1988.

TRussel, R.P. The percent un-ionizide ammonia aqueous ammonia solutions at different $\mathrm{pH}$ levels and temperature. Journal of the Fisheries Research Board of Canada, v.29, p.1905-1907, 1972.

Recebido em 19/5/06

Aceito em 6/10/06 